\title{
Examining the Effect of Acute Whole-Body Vibration on Static and Dynamic Balance in Physical Education Students
}

\author{
Duygu Aksoy ${ }^{1}$ \\ ${ }^{1}$ School of Physical Education and Sports, Namik Kemal University, Tekirdag, Turkey \\ Correspondence: Duygu Aksoy, School of Physical Education and Sports, Tekirdağ Namık Kemal University, \\ Tekirdağ, Turkey. E-mail: duyguaksoy@nku.edu.tr
}

Received: July 19, 2019

doi:10.5539/jel.v8n5p142
Accepted: August 21, 2019 Online Published: September 20, 2019

URL: https://doi.org/10.5539/jel.v8n5p142

\begin{abstract}
The purpose of the present study was to examine the effect of acute Whole Body Vibration (WBV) on static and dynamic balance in physical education students. A total of 30 healthy physical education students participated in this study. The participants were divided into two groups as the Control Group $(\mathrm{n}=15)$ and the Whole Body Vibration group $(\mathrm{n}=15)$. The control group did not carry out any trainings; and the WBV group did acute WBV. The first measurements of height, weight, flamingo balance test for static balance, and the $\mathrm{Y}$ balance test for dynamic balance were made for both groups before applying the WBV program. The final measurements were made right after the WBV application. Results are presented as mean \pm standard deviation. The values that were obtained from the pre-test and post-test were analyzed with the paired sample t-test after their normality was checked with the Shapire-Wilk Test. The comparisons between the groups were analyzed by using an independent sample $t$-test at a significance level of $p<0.05$. The flamingo balance test was applied to determine the static balance values. According to the flamingo balance test, there was a significant difference between the right leg pre-test and post-test values of the WBV group $(p<0.05)$. A significant difference was detected between the left leg pre-test and post-test values of the WBV group $(p<0.05)$. The $Y$ balance test was applied to determine the dynamic balance results. There was a significant difference between the right leg pre-test and post-test values of the WBV group $(\mathrm{p}<0.05)$. There was a significant difference between the left leg pre-test and post-test values of the WBV group. It was determined that the acute WBV has a positive effect on static and dynamic balance.
\end{abstract}

Keywords: whole body vibration, static balance, dynamic balance

\section{Introduction}

Balance may be defined as whether or not a person can move around the ankle and hip joints or the joints in both areas (Nashner \& Mccollum, 1985). Balance is also the ability to keep the center of weight of the body over the support base (Boccolini et al., 2013).

Balance is the sole important element that affects the movement strategies in the closed kinetic chain. In addition, it is also the most important component of the athletic ability because it covers almost all forms of movement (Blackburn et al., 2000; Matsuda et al., 2008).

Optimal balance occurs as a response to the continuous feedback of the visual, vestibular and somatosensory system with neuromuscular effects. This adjusts and maintains the correct body position in a continuous manner (Boccolini et al., 2013; Winter et al., 1990; Oiala et al., 1989; Voorhes, 1990; Lip \& Longride, 1994).

Balance is examined in two ways as Static and Dynamic Balance. Static Balance is the ability to maintain the position of the center of gravity in situations that involve little mobility (Hockey, 1981). Dynamic Balance is defined as the neutralization of the external forces that act on the body by muscles and soft tissues around the joints (Brown \& Weir, 2001).

Body balance and stability require constant attention and the protection of muscle strength (Chandler \& Hadley, 1996). Unstable surface trainings are included frequently in traditional training and physical therapy rehabilitation programs. In addition, they may also be added to programs that are applied to prevent injuries in sports or other injuries in daily life or to prevent the risk of falling (Lehman et al., 2005). It is considered that unstable surface will increase the difficulty of exercises, and depending on this, also increase muscle activity that 
forces the body to stabilize (Lehman et al., 2005; Lehman et al., 2006).

Whole Body Vibration (WBV) Training is a new unstable surface training technique that is recommended as an alternative to endurance training. In addition, WBV training is also used as a popular warm-up, cool-down or training technique (Di Giminiani et al., 2010; Mahiu et al., 2006; Marin et al., 2012; Torvinen et al., 2002a; Torvinen et al., 2003; Van Nes et al., 2004).

WBV was first used in Russia in 1980s to increase the sporting performance (Issurin, 1994). It is preferred in gyms and rehabilitation centers since it is easy to apply and requires little technical skills (Marin, 2010).

The data of previous studies support the positive effects of Whole Body Vibration on balance (Despina et al., 2014). However, studies that investigate the effects of Whole Body Vibration Training on the balance of trained athletes and non-training individuals are limited (Fort et al., 2012; Despina et al., 2014; Torvinen et al., 2002b).

In previous studies, the effects of long-term and short-term Whole Body Vibration Training on balance, postural release and control were reported to be equal (Marin et al., 2012; Torvinen et al., 2003; Cardinale \& Lim, 2003; Gusi et al., 2006).

In a study, the effects of two-amplitude WBV on balance were investigated. In eighteen young healthy individuals, it was reported that the amplitude did not affect the joint position perception and static balance. However, little is known about the effects of Vibration Training on static balance (Pollock et al., 2011).

The purpose of the present study is to examine the effect of Acute WBV on static and dynamic balance in physical education students.

\section{Material and Method}

\subsection{Participants}

A total of 30 healthy physical education students whose ages varied between 18 and 25 years, who did not do regular sports, who did not have any health problems, who agreed to participate in the present study voluntarily, who did not have any neurological medical history, were included in the study. The participants were randomly divided into two groups as the WBV Group $(\mathrm{n}=15)$ and the control Group $(\mathrm{n}=15)$. WBV group $(21.47 \pm 2.23$ years, $175.23 \pm 5.41$ height, $75.56 \pm 1.68$ weight), control group $(21.26 \pm 2.13$ years, $174.58 \pm 8.77$ height, $71.83 \pm$ 1.42 weight).

The exclusion criteria were having any prosthesis, having any disease disrupting the bone mechanism or muscles, having neurologic diseases, chronic inflammatory diseases and having no injury or medical surgery related to lower and upper extremities that could influence the test results. The participants did not have any previous experience on WBV; and were told not to eat at the last $1.5 \mathrm{~h}$ before the test and not to do any vigorous training one day before. The participants were allowed to drink water in all tests.

The informing document was given to the participants about the tests to be conducted and their voluntary participation was asked. Students were informed about the procedures that would be done during the study.

\subsection{Study Procedure}

The control group did not do any training; and the WBV group did acute WBV. The WBV trainings were performed on the Vibration Platform (Aspire 588, Istanbul, Turkey). The participants had 10-minute light-tempo walking and warm-up exercises before the WBV.

The WBV group applied WBV on the platform at $40 \mathrm{~Hz}$. frequency, $2 \mathrm{~mm}$. amplitude, $60 \mathrm{sn}$ duration for squat exercise; $40 \mathrm{~Hz}$ Frequency, $4 \mathrm{~mm}$ amplitude, for 60 seconds for deep squat exercise; at $40 \mathrm{~Hz}$ Frequency, $4 \mathrm{~mm}$ amplitude, 60 seconds for toes stand exercise; at $50 \mathrm{~Hz}$ Frequency, $4 \mathrm{~mm}$ amplitude, 60 seconds, respectively. Among the exercises, 30 seconds resting time was given.

The initial measurements were made for both groups for height, weight, static balance and dynamic balance of the participants before applying the acute WBV Program. The final measurements were made right after the acute WBV application.

\subsection{The Measurements and Tests Applied}

\subsubsection{Height and Weight Measurements}

A digital scale (Seca 664, Hamburg, Germany) was used in body height and weight measurements in bare feet and wearing only shorts.

\subsubsection{Static Balance Measurement}

The Flamingo Balance Test: The static balance measurements of the subjects who participated in the study were 
made with the Flamingo Balance Tool. In this test, which measures the general body balance, a metal beam that was $50 \mathrm{~cm}$ long, $4 \mathrm{~cm}$ high, $3 \mathrm{~cm}$ wide, was covered with a non-slip substance, with a thickness of no more than $5 \mathrm{~mm}$ was employed. For the height of the beam, feet that were $15 \mathrm{~cm}$ long and $2 \mathrm{~cm}$ wide were placed at each end of the beam.

The duration of standing with one leg on the balance iron of the subjects was tested. The free leg was held on the same side by the hand, the knee was bent, and the free hand was supported by the tester. As soon as the subject felt that he could stay on balance, s/he left the hand of the tester, and at this time, the stopwatch was started. When the leg if the subject left the balance iron and when the balance was disrupted, the stopwatch was stopped. The participant tried to remain in balance for one minute after each falling (Deforche et al., 2003; Sundsrup et al., 2010; Krustrup et al., 2010). The test was done for the right and the left leg separately.

\subsubsection{Dynamic Balance Measurement}

Y Balance Test: The Dynamic Balance Measurements of the subjects were made by the Y Balance Test. Three lines were drawn in anterior, anteromedial and posterolateral directions with $120^{\circ}$ angle among them. The athletes were required to stand on the starting point, where the lines intersected. According to the pre-determined protocol, while the subjects were on balance on one leg, the other leg was asked to stretch in three directions with the fingertip in the shape of a "y". Care was given not to lose the balance of the subject, not to stand on the heel of the leg the subject was standing on, touch the fingertips of the leg the subject had stretched slightly, and bring the stretched leg to the stable foot without touching the ground. The test was repeated 3 times with 15 -sec resting intervals for each direction and the best score that was received was recorded in $\mathrm{cm}$ (Kinzey \& Armstrong, 1998; Plisky et al., 2006; Plisky et al., 2009). The test was repeated for the right and left feet.

\subsection{Statistical Analysis}

Results are presented as mean \pm standard deviation. The values that were obtained from the pre-test and post-test were analyzed with the paired sample $t$ test in terms of their differences after the normality was checked with the Shapire-Wilk Test. The comparisons between the groups were made by using the independent samples t-test at $\mathrm{p}$ $<0.05$ significance level.

\section{Results}

The pre-test and post-test scores of the WBV group and the control group in the flamingo balance test and the Y balance test are given below.

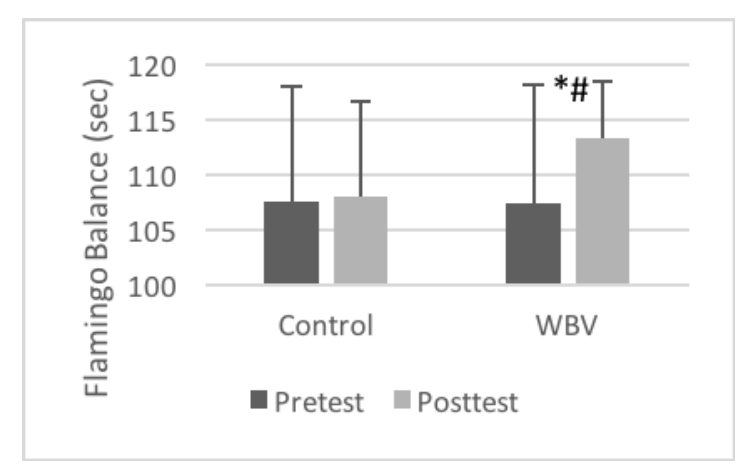

Figure 1. The mean and standard deviation right leg pre and post flamingo balance scores of the for WBV group and control group

Note. ${ }^{*} \mathrm{p}<0.05$ significantly differences between pre and post value for each group. $\# \mathrm{p}<0.05$ significantly differences between groups.

According to the right leg flamingo balance test results, it was determined that there was a significant difference in the comparison of the pre-test and post-test flamingo balance performance scores of the participants in the WBV group $(\mathrm{p}=.011, \mathrm{p}<0.05)$. There was a statistically significant difference in the post-test results of the groups $(\mathrm{p}=.008, \mathrm{p}<0.05)$. 


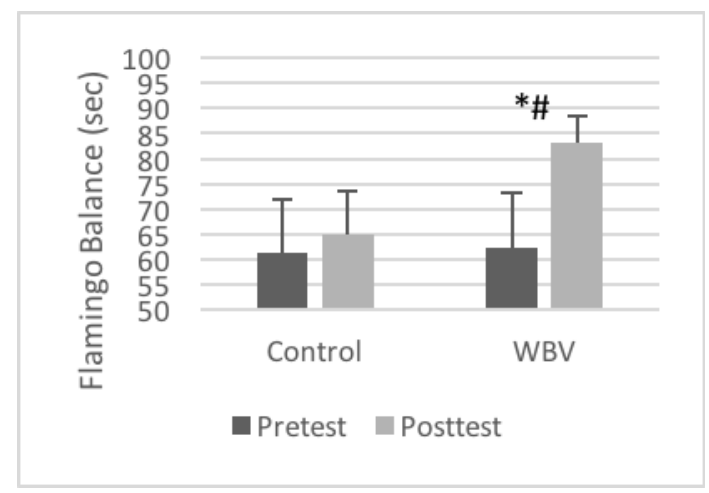

Figure 2. The mean and standard deviation left leg pre and post flamingo balance scores of the for WBV group and control group

Note. ${ }^{*} \mathrm{p}<0.05$ significantly differences between pre and post value for each group. $\# \mathrm{p}<0.05$ significantly differences between groups.

According to the results of the left leg flamingo balance test, it was determined that there was a significant difference in the comparison of the WBV group of ten test-post-test $(p=.006, p<0.05)$. There was a statistically significant difference in the results of the end-group test $(\mathrm{p}=.013, \mathrm{p}<0.05)$. There was a statistically significant difference in the post-test results of the groups $(\mathrm{p}=.023, \mathrm{p}<0.05)$, (Figure 2$)$.

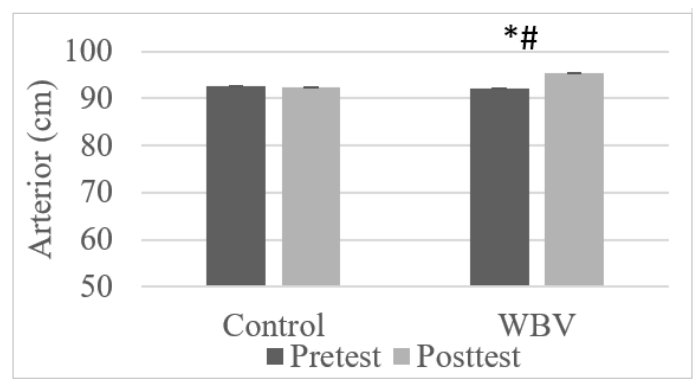

Figure 3. The mean and standard deviation right leg pre and post Arterior scores of the for WBV group and control group

Note. ${ }^{*} \mathrm{p}<0.05$ significantly differences between pre and post value for each group. $\# \mathrm{p}<0.05$ significantly differences between groups.

According to the $\mathrm{Y}$ balance test results, there was an increase at a statistically significant level between the pre-test and post-test scores of the WBV group for right leg arterior values $(\mathrm{p}=.013, \mathrm{p}<0.05)$. There was a statistically significant difference in the post-test results of the groups $(\mathrm{p}=.016, \mathrm{p}<0.05)$, (Figure 3).

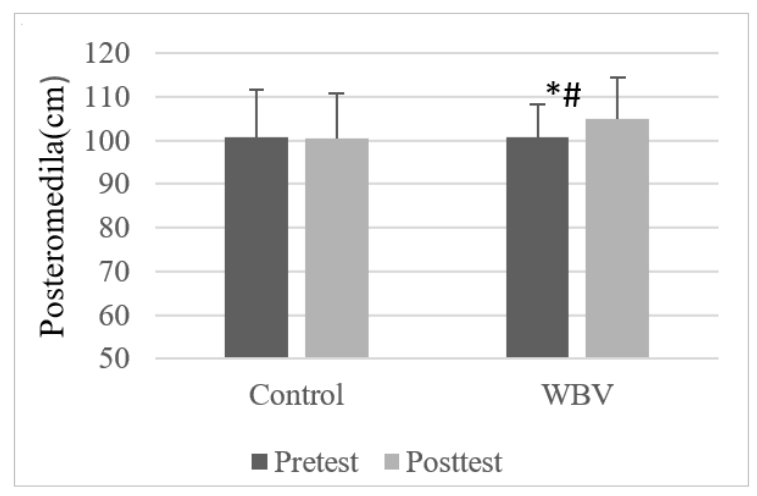

Figure 4. The mean and standard deviation right leg pre and post Posteromedial scores of the for WBV group and control group

Note. ${ }^{*} \mathrm{p}<0.05$ significantly differences between pre and post value for each group. $\# \mathrm{p}<0.05$ significantly differences between groups. 
According to the $\mathrm{Y}$ balance test results, there was a statistically significant increase in the pre-test and post-test scores of the WBV group in the right leg posteromedial values $(p=.034, p<0.05)$. There was a statistically significant difference in the post-test results of the groups $(p=.021, \mathrm{p}<0.05)$, (Figure 4$)$.

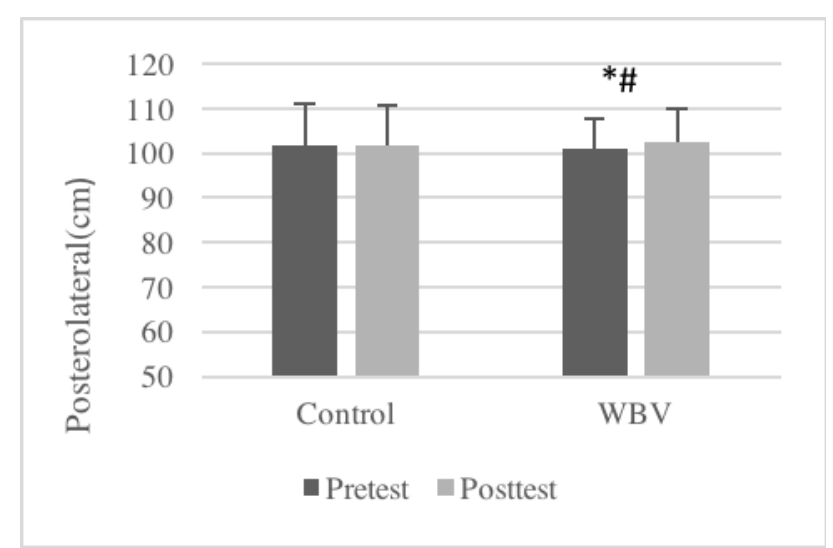

Figure 5. The mean and standard deviation right leg pre and post Posterolateral scores of the for WBV group and control group

Note. ${ }^{*} \mathrm{p}<0.05$ significantly differences between pre and post value for each group. $\# \mathrm{p}<0.05$ significantly differences between groups.

According to the $\mathrm{Y}$ balance test results, there was a statistically significant and positive increase in the pre-test and post-test scores of the WBV group in the right leg posterolateral values for the WBV group in the pre-test and post-test values $(\mathrm{p}=.011, \mathrm{p}<0.05)$. There was a statistically significant difference in the post-test results of the groups $(\mathrm{p}=.035, \mathrm{p}<0.05)$, (Figure 5).

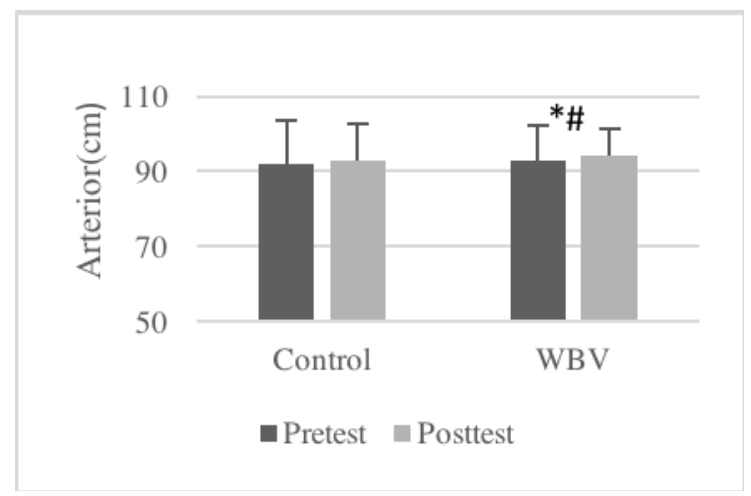

Figure 6. The mean and standard deviation left leg pre and post Arterior scores of the for WBV group and control group

Note. ${ }^{*} \mathrm{p}<0.05$ significantly differences between pre and post value for each group. $\# \mathrm{p}<0.05$ significantly differences between groups.

According to the $\mathrm{Y}$ balance test results, there was a positive and significant increase in the left leg arterior values of the WBV group between the pre-test and post-test scores $(p=.042, p<0.05)$ There was a statistically significant difference in the post-test results of the groups $(p=.011, p<0.05)$, (Figure 6). 


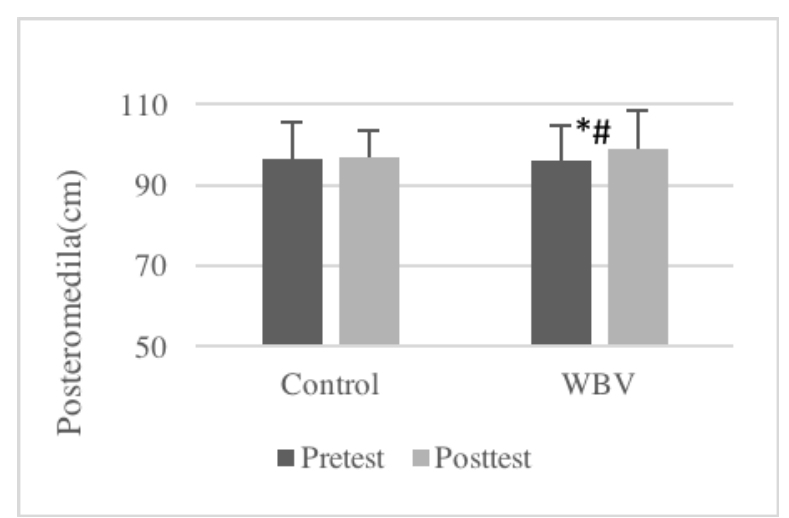

Figure 7. The mean and standard deviation left leg pre and post Posteromedial scores of the for WBV group and control group

Note. ${ }^{*} \mathrm{p}<0.05$ significantly differences between pre and post value for each group. $\# \mathrm{p}<0.05$ significantly differences between groups.

According to the Y balance test results, the pre-test and post-test scores of the WBV group in the left leg posteromedial are shown (Figure 7). There was a statistically significant increase between the pre-test and post-test scores of the WBV group $(\mathrm{p}=.010, \mathrm{p}<0.05)$. There was a statistically significant difference in the post-test results of the groups $(\mathrm{p}=.014, \mathrm{p}<0.05)$, (Figure 7).

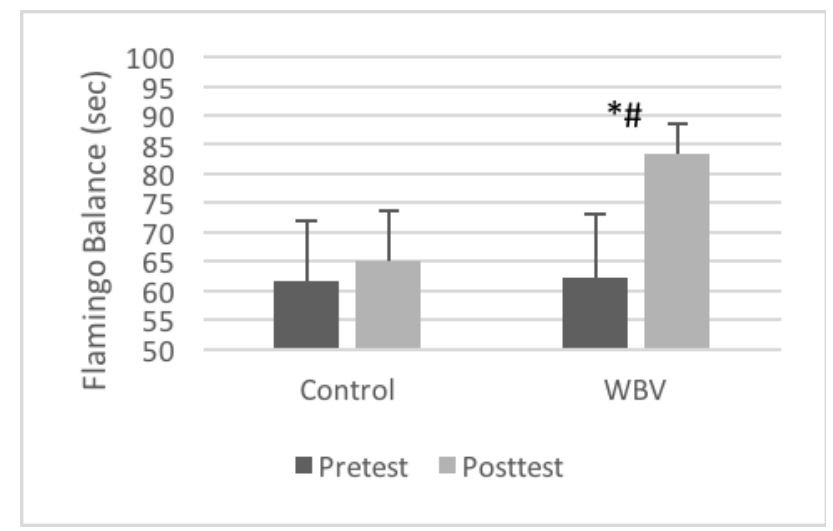

Figure 8. The mean and standard deviation left leg pre and post posterolateral scores of the for WBV group and control group

Note. ${ }^{*} \mathrm{p}<0.05$ significantly differences between pre and post value for each group. $\# \mathrm{p}<0.05$ significantly differences between groups.

According to the $\mathrm{Y}$ balance test results, the pre-test and post-test scores in the left leg posterolateral values are shown (Figure 8). There was a statistically significant increase between the pre-test and post-test scores of the WBV group $(\mathrm{p}=.012, \mathrm{p}<0.05)$. There was a statistically significant difference in the post-test results of the groups $(\mathrm{p}=.018, \mathrm{p}<0.05)$.

\section{Discussion and Conclusion}

In this study, the effect of acute WBV that was applied to physical education students on static and dynamic balance was examined. The participants were divided randomly into two groups. There was a positive development after the acute WBV in dynamic and static balance results. The difference between the pre-test and post-test scores was determined to be significant. In addition, the difference between the post-test scores of the WBV group and the control group were determined to be significant.

In many studies, Vibration Training was reported to increase the balance in elderly people (Kawanabe et al., 2007; Rees et al., 2008), in patients with motor control disorder due to Parkinson's Disease (Ebersbach et al., 2008; Schuhfried et al., 2005), in paralyzed patients (van Nes et al., 2006; Tihanyi et al., 2007) and in patients with Multiple Sclerosis (Mason et al., 2012). According to these results, it provides evidence for the balance 
control of individuals who are healthy and well-educated.

In studies conducted on the effect of long-term WBV Training on balance, improvements were reported on balance in the first 8 weeks of the 15-week WBV Training that was applied to elite female basketball players (Fort et al., 2012). In addition, similar results were reported in studies that were conducted on individuals who did not do any training (Bogaerts et al., 2007; Torvinen et al., 2002a, 2002b).

According to another study, 4-month WBV study showed no significant changes in static or dynamic balance on healthy nonathletic volunteers (Torvinen et al., 2002b).

In previous studies, positive effects of WBV Training were observed on balance of elderly individuals (Jacobs \& Burns, 2009; Adams et al., 2009), proprioceptive posture control, and one-foot maximum stance (Kawanabe et al., 2007; Gusi et al., 2006). In another study, no significant differences were determined in postural control in young skiers at the end of Whole Body Vibration Training (Mahieu et al., 2006).

The acute effects of 4-minute WBV yielded positive improvements in lower extremity strength and balance (Torvinen et al., 2002). It was found that the body balance was improved in positive way at a rate of $16 \%$ two minutes after WBV (Torvinen et al., 2002). In addition, long-term 8-month WBV Training program did not improve the balance (Torvinen et al., 2003).

According to the literature, a great number of the previous studies were conducted with elderly individuals on the effect of WBV on balance. In many studies, it was determined that long-term WBV had positive effects on balance. The few studies that were conducted on healthy individuals examined the effects of short term WBV on balance. In this respect, to reach different results, there is a need that will be conducted on the effects of acute WBV especially on individuals who do regular sports.

\section{References}

Adams, J. B., Edwards, D., Serviette, D., Bedient, A. M., Huntsman, E., Jacobs, K. A., Del Rossi, G., \& Signorile, J. F. (2009). Optimal frequency, displacement, duration, and recovery patterns to maximize power output following acute whole-body vibration. Journal of Strength and Conditioning Research, 23, 237-245. https://doi.org/10.1519/JSC.0b013e3181876830

Blackburn, T., Guskiewicz, K. M., Petschauer, M. A., \& Prentice, W. E. (2000). Balance and joint stability: the relative contributions of proprioception and muscular strength. Journal of Sport Rehabilitation, 9, 315-328. https://doi.org/10.1123/jsr.9.4.315

Boccolini, G., Brazzit, A., Bonfanti, L., \& Alberti, G. (2013). Using balance training to improve the performance of youth basketball players. Sport Sciences for Health, 9(2), 37-42. https://doi.org/10.1007/s11332-013-0143-z

Bogaerts, A., Verschueren, S., Delecluse, C., Claessens, A. L., \& Boonen, S. (2007). Effects of whole body vibration training on postural control in older individuals: A 1 year randomized controlled trial. Gait and Posture, 26, 309-316. https://doi.org/10.1016/j.gaitpost.2006.09.078

Brown, L. E., \& Weir, J. P. (2001). Asep procedures recommendation I: accurate assessment of muscular strength and power. Journal of Exercise Physiolology, 4(11), 121.

Cardinale, M., \& Lim, J. (2003). Electromyography activity of vastuslateralis muscle during whole-body vibrations of different frequencies. Journal of Strength and Conditioning Research, 17, 621-624. https://doi.org/10.1519/00124278-200308000-00032

Chandler, J. M., \& Hadle E. C. (1996). Exrcise to improve physiologic and functional performance in olde age. Clinics in Geriatric Medicine, 12, 761-784. https://doi.org/10.1016/S0749-0690(18)30200-3

Deforche, B., Lefevre, J., De Bourdeaudhuji, I., Hills, A. P., Duquet, W., \& Bouckaert, J. (2003). Physical fitness and physical activity in obese and nonobese Flemish youth. Obesity Research and Clinical Practice, 11, 434-441. https://doi.org/10.1038/oby.2003.59

Despina, T., George, D., George, T., Sotiris, P., Alessandra, D. C., George, K., Maria, R., \& Stavros, K. (2014). Short-term effect of whole-body vibration training on balance, flexibility and lower limb explosive strength in elite rhythmic gymnasts. Human Movement Science, 33, 149-158. https://doi.org/10.1016/j.humov.2013.07.023

Di Giminiani, R., Manno, R., Scrimaglio, R., Sementilli, G., \& Tihanyi, J. (2010). Effects of individualized whole-body vibration on muscle flexibility and mechanical power. Journal of Sports Medicine and Physical Fitness, 50, 139-151. 
Ebersbach, G., Edler, D., Kaufhold, O., \& Wissel, J. (2008). Whole body vibration versus conventional physiotherapy to improve balance and gait in Parkinson's disease. Archives of Physical Medicine and Rehabilitation, 89(3), 399-403. https://doi.org/10.1016/j.apmr.2007.09.031

Fort, A., Romero, D., Bagur, C., \& Guerra, M. (2012). Effects of whole body vibration training on explosive strength and postural control in young female athletes. Journal of Strength and Conditioning Research, 26, 926-936. https://doi.org/10.1519/JSC.0b013e31822e02a5

Gusi, N., Raimundo, A., \& Leal, A. (2006). Low-frequency vibratory exercise reduces the risk of bone fracture more than walking: a randomized controlled trial. BMC Musculoskeletal Disorders, 7, 1-8. https://doi.org/10.1186/1471-2474-7-92

Hockey, R. V. (1981). Skill and motor ability physical fitness: The patway to healthful living (4th ed., pp. 113-118). St. Louis Toronto, London.

Issurin, V. B., Liebermann, D. G., \& Tenebaum, G. (1994). Effect of vibratory stimulation training on maximal force and flexibility. Journal of Sports Science, 12(6), 561-566. https://doi.org/10.1080/02640419408732206

Jacobs, P. L., \& Burns, P. (2009). Acute enhancement of lower-extremity dynamic strength and flexibility with whole-body vibration. Journal of Strength and Conditioning Research, 23, 51-57. https://doi.org/10.1519/JSC.0b013e3181839f19

Kawanabe, K., Kawashima, A., Sashimoto, I., Takeda, T., Sato, Y., \& Iwamoto, J. (2007). Effect of whole-body vibration exercise and muscle strengthening, balance, and walking exercises on walking ability in the elderly. Keio Journal of Medicine, 56(1), 28-33. https://doi.org/10.2302/kjm.56.28

Kinzey, S. J., \& Armstrong, C. W. (1998). The reliability of the Star-Excursion Test in assessing dynamic balance. Journal of Orthopaedic \& Sports Physical Therapy, 27, 356-360. https://doi.org/10.2519/jospt.1998.27.5.356

Krustrup, P., Christensen, J. F., Randers, M. B., Pedersen, H., Sundstrup, E., Jakobsen, M. D., Krustrup, B. R., Nielsen, J. J., Suetta, C., Nybo, L., \& Bangsbo, J. (2010). Muscle adaptations and performance enhancements of soccer training for untrained men. European Journal of Applied Physiology, 108(6)., 1247-1258. https://doi.org/10.1007/s00421-009-1319-8

Lehman, G. J., Gordon, T., Langley, J., Pemrose, P., \& Tregaskis, S. (2005). Replacing a swiss ball for an exercise bench causes variable changes in trunk muscle activity during upper limb strength exercises. Dynamic Medicine, 4, 6. https://doi.org/10.1186/1476-5918-4-6

Lehman, G. J., Mac Millan, B., MacIntyre, I., Chivers, M., \& Fluter, M. (2006). Shoulder muscle EMG activity during push up variations on and off a swiss ball. Dynamic Medicine, 2, 5. https://doi.org/10.1186/1476-5918-5-7

Lipp, M., \& Longridge, N. S. (1994). Computeraized dynamic posturography: its place in the evaluation of patients with dizziness and imbalance. Journal of Otolaryngology, 23(3), 177-183.

Mahieu, N. N., Witvrouw, E., Van de Voorde, D., Michilsens, D., Arbyn, V., \& Van den Broecke, W. (2006). Improving strength and postural in young skiers: whole-body vibration versus equivalent resistance training. Journal of Athletic Training, 41, 286-293.

Marin, P. J., \& Rhea, M. R. (2010). Effects of vibration training on muscle power: a meta-analysis. Journal of Strength and Conditioning Research, 24(3), 871-878. https://doi.org/10.1519/JSC.0b013e3181c7c6f0

Marin, P. J., Zarzuela, R., Zarzosa, F., Herrero, A. F., Garatachea, N., Rhea, M. R., \& Garcia-Lopez, D. (2012). Whole-body vibration as a method of recovery for soccer players. European Journal of Sport Science, 12, 2-8. https://doi.org/10.1080/17461391.2010.536579

Mason, R. R., Cochrane, D. J., Denny, G. J., Firth, E. C., \& Stannard, S. R. (2012). Is 8 weeks of side-alternating whole-body vibration a safe and acceptable modality to improve functional performance in multiple sclerosis. Disability and Rehabilitation, 34(8), 647-654. https://doi.org/10.3109/09638288.2011.615370

Matsuda, S., Demura, S., \& Uchiyama, M. (2008). Center of pressure sway characteristics during static one-legged stance of athletes from different sports. Journal Sport Sciences, 26, 775-779. https://doi.org/10.1080/02640410701824099

Nashner, L. M., \& Mccollum, G. (1985). The organization of human postural movements: a formal basis and experimental synthesis. Behavioral and Brain Sciences, 8, 135-172. 
https://doi.org/10.1017/S0140525X00020008

Ojala, M., Matikainen, E., \& Juntunen, J. (1989). Posturography and the dizzy patient: a neurological study of 133 patients. Acta Neurologica Scandinavica, 80(2), 118-122. https://doi.org/10.1111/j.1600-0404.1989.tb03852.x

Plisky, P. J., Gorman, P. P., Butler, R. J., Kiesel, K. D. Underwood, F. B., \& Elkins, B. (2009). The reliability of an instrumented device for measuring components of the star excursion balance test. North American Journal of Sports Physical Therapy, 4(2), 92-99.

Plisky, P. J., Rauh, M. J., Kaminski, T. W., \& Underwood, F. B. (2006). Star excursion balance test as a predictor of lower extremity injury in high school basketball players. Journal of Orthopaedic \& Sports Physical Therapy, 36, 911-919. https://doi.org/10.2519/jospt.2006.2244

Pollock, R. D., Provan, S., Martin, F. C., \& Newham, D. J. (2011). The effects of whole body vibration on balance, joint position sense and cutaneous sensation. European Journal of Applied Physiology, 111, 3069-3077. https://doi.org/10.1007/s00421-011-1943-y

Rees, S. S., Murphy, A. J., \& Watsford, M. L. (2008). Effects of whole-body vibration exercise on lower-extremity muscle strength and power in an older population: a randomized clinical trial. American Physical Therapy Association, 88(4), 462-470. https://doi.org/10.2522/ptj.20070027

Schuhfried, O., Mittermaier, C., Jovanovic, T., Pieber, K., \& Paternostro-Sluga, T. (2005). Effects of whole-body vibration in patients with multiple sclerosis: a pilot study. Clinical Rehabilitation, 19(8), 834-842. https://doi.org/10.1191/0269215505cr919oa

Sundstrup, E., Jakobsen, M. D., Andersen, J. L., Randers, M. B., Petersen, J., Suetta, C., Aagaard, P., \& Krustrup, P. (2010). Muscle function and postural balance in lifelong trained male footballers compared with sedentary elderly men and youngsters. Scandinavian Journal of Medicine and Science in Sports, 20(Suppl 1), 90-97. https://doi.org/10.1111/j.1600-0838.2010.01092.x

Tihanyi, T. K., Horvath, M., Fazekas, G., Hortobagyi, T., \& Tihanyi, J. (2007). One session of whole body vibration increases voluntary muscle strength transiently in patients with stroke. Clinical Rehabilitation, 21(9), 782-793. https://doi.org/10.1177/0269215507077814

Torvinen, S., Kannus, P., Sievanen, H., Jarvinen, T., Pasanen, M., Kontulainen, S., Jarvinen, T. L., Jarvinen, M., Oja, P., \& Vuori, I. (2002a). Effect of a vibration exposure on muscular performance and body balance. Randomized cross-over study. Clinical Physiology and Functional Imaging, 22, 145-152. https://doi.org/10.1046/j.1365-2281.2002.00410.x

Torvinen, S., Kannus, P., Sievanen, H., Jarvinen, T. A. H., Pasanen, M., Kontulainen, S. T., Jarvinen, T. L., Jarvinen, M., Oja, P., \& Vuori, I. (2002b). Effect of four-month vertical whole body vibration on performance and balance. Medicine and Science in Sports and Exercise, 34, 1523-1528. https://doi.org/10.1097/00005768-200209000-00020

Torvinen, S., Kannus, P., Sievanen, H., Jarvinen, T., Pasanen, M., Kontulainen, S., Nenonen, A., Jarvinen, T. L., Paakkale, T., \& Vuori, I. (2003). Effect of 8-month vertical whole body vibration on bone, muscle performance and body balance: a randomized controlled study. Journal of Bone and Mineral Research, 18, 876-884. https://doi.org/10.1359/jbmr.2003.18.5.876

Van Nes, I. J., Geurts, A. C., Hendricks, H. T., \& Duysens, J. (2004). Short-term effects of whole-body vibration on postural control in unilateral chronic stroke patients: preliminary evidence. American Journal of Physical Medicine and Rehabilitation, 83, 867-873. https://doi.org/10.1097/01.PHM.0000140801.23135.09

van Nes, I. J. W., Latour, H., Schils, F., Meijer, R., van Kuijk, A., \& Geurts, A. C. (2006). Long-term effects of 6-week whole-body vibration on balance recovery and activities of daily living in the postacute phase of stroke: a randomized, controlled trial. Stroke, 37(9), 2331-2335. https://doi.org/10.1161/01.STR.0000236494.62957.f3

Voorhees, R. L. (1990). Dynamic posturography findings incentral nervous system disorders. Otolaryngology-Head and Neck Surgery, 103(1), 96-101. https://doi.org/10.1177/019459989010300114

Winter, D. A., Patla, A. E., \& Frank, J. S. (1990). Assessment of balance control in humans. Medical Progress Through Technology, 16(1-2), 31-51. 


\section{Copyrights}

Copyright for this article is retained by the author, with first publication rights granted to the journal.

This is an open-access article distributed under the terms and conditions of the Creative Commons Attribution license (http://creativecommons.org/licenses/by/4.0/). 